Conclusion The best solutions are often simple, yet unexpected Julian Casablancas

Although it took time to sort out the processes required it is now routine and as easy as outsourcing to any supplier. The initial reluctance of some to involve with HMP was quickly overcome and very positively received by our community. I would encourage everyone to look locally for solutions; in a world that has become smaller through the internet we often lose sight of the skills and opportunities right under our noses.

\section{P-254 SEVENTEEN AND SUPER KEEN; YOUNG PEOPLE VOLUNTEERING ON AN IN-PATIENT UNIT}

Clair Sadler, Zoe Byrne. Princess Alice Hospice, Esher, UK

\subsection{6/bmjspcare-2016-001245.274}

In September 2015, we introduced an innovative new volunteering programme aimed at 17 -year-olds interested in a career in healthcare. The Ward Support Volunteers committed to a unique six-month programme involving supporting healthcare assistants on our large in-patient unit and working towards the Care Certificate qualification.

The objectives were to:

- create a sustainable programme that increased resource on the in-patient unit

- provide a meaningful opportunity for young people interested in healthcare

- diversify the volunteer workforce.

The role description included talking with patients and relatives, assisting with meals and drinks and replenishing stock. All local schools and colleges were contacted to publicise the opportunity and 22 young people were interviewed.

The Education team delivered a bespoke experiential induction day for the 14 selected volunteers that explored communication skills as well as practical training like hand massage.

We also developed a workbook to accredit the programme under the new Care Certificate which included practical activities and online learning. Experienced volunteers acted as 'Buddies', regularly meeting with the young volunteers to support them.

Thirteen young people completed the programme and received the Care Certificate. The main gain for the volunteers, however, was an increase in their confidence and ability to communicate.

"I don't think I would have got medicine offers without it but, more importantly, it has made me a much more confident and compassionate person.” Robyn, 17

"The ward support volunteers have been a fantastic addition to the ward. They inject some much needed energy when they arrive at $4.30 \mathrm{pm}$ and to have enthusiastic, inquisitive young people on the ward has benefited the staff as well as the patients and visitors." Senior Staff Nurse

The programme continues with the second cohort also being trained in basic manual handling to make their role even more valuable to the ward.

\section{P-255 BUILDING PARTNERSHIPS BY DEVELOPING A VOLUNTEERING STRATEGY}

Katherine Perrin. St Catherine's Hospice, Crawley, UK
Introduction McCurley, Lynch and Jackson (2012) suggest that volunteers are an underused resource and that volunteers can and should make a significant contribution to an organisation's strategic objectives. St Catherine's currently has more than 800 volunteers.

Aim To set the strategic direction for volunteering, recognising the central role volunteers play in the delivery of services and support functions. A compelling and collaborative vision was needed to unite all services behind the ambition to enhance how we recruit, induct, value, celebrate, and develop volunteers, as well as innovating how they are included in the delivery of our services.

Method In 2014-15 every line manager across the organisation was consulted, exploring strengths, challenges and ambitions. The volunteer development manager shadowed existing volunteers, analysed how well we articulate our vision and the appetite for revolutionising our approach. Finally a gap analysis of our position against key national standards, including Investing in Volunteers, was undertaken to benchmark our approach.

Having established our baseline and emerging themes, our objectives and key activities were drafted. All volunteers were consulted via email and a breakfast event. Feedback was used to consolidate these objectives, create a vision and flesh out key activities. The project group of managers and a volunteer representative were asked to review the full draft before Senior Management signed off the strategy.

Results The organisation's first ever Volunteering Strategy was published in the summer of 2015. It recognises that volunteers are some of the biggest donors to the hospice and their time is priceless. It sets out an ambitious vision to be the organisation of choice for volunteers - to hold a reputation of volunteering excellence and demonstrate best practice in all that it does.

\section{P-256 DEVELOPING OUR PEOPLE - ESTABLISHING A NEW TRAINING PROGRAMME FOR VOLUNTEERS}

Katherine Perrin. St Catherine's Hospice, Crawley, UK

\subsection{6/bmjspcare-2016-001245.276}

Introduction Skogland suggests that effective training "results in volunteers' willingness to participate in the agency's volunteer program for a significant period of time” (Skogland 2006).

Aim To invest in our $800+$ volunteers by delivering essential training, to refresh key skills and competencies, improve confidence and encourage volunteers to share and gain new expertise. Method Of our four categories of volunteer (clinical, non-clinical, retail and community), we prioritised clinical and set up a project group of clinical managers and the volunteering development manager. Content was influenced by legal and policy requirements, general information for all volunteers and specific competencies needed, with managers leading on their skill areas.

During the day, volunteers explored the challenges of communicating, safeguarding, setting boundaries and volunteering safely. Working through scenarios and practical exercises, volunteers learnt from clinicians as well as each other, with a strong focus on insights into life as a patient.

One important aim is to transform all hospice volunteers into Dementia Friends, and this work will create more than 240 new Dementia Friends supporting our work and using this knowledge in their everyday lives. 